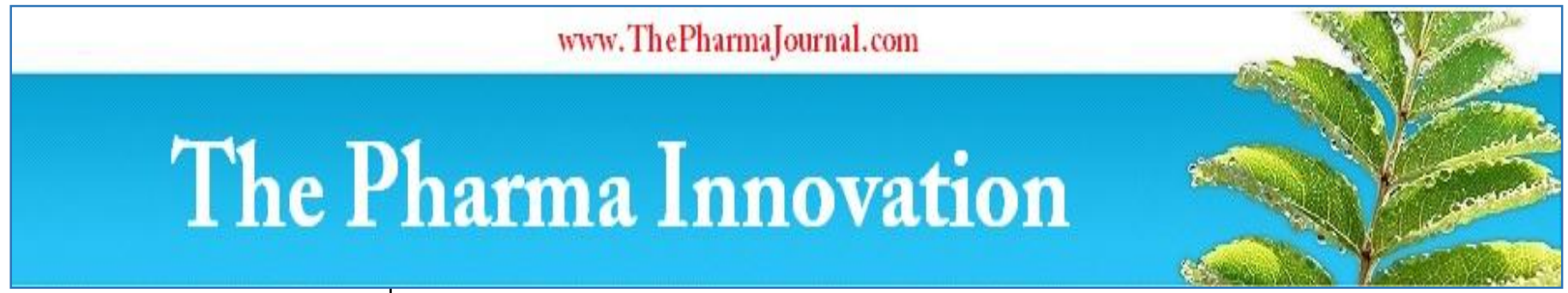

ISSN (E): 2277 - 7695

ISSN (P): 2349-8242

NAAS Rating 2017: 5.03

TPI 2017; 6(11): 815-816

(C) 2017 TPI

www.thepharmajournal.com

Received: 22-09-2017

Accepted: 23-10-2017

\section{Arghya Banerjee}

Department of Plant Pathology, Bidhan Chandra Krishi

Viswavidyalaya, Mohanpur,

Nadia, West Bengal, India

\section{Partha Sarathi Nath}

Department of Plant Pathology, Bidhan Chandra Krishi

Viswavidyalaya, Mohanpur,

Nadia, West Bengal, India
Correspondence

Arghya Banerjee

Department of Plant Pathology,

Bidhan Chandra Krishi

Viswavidyalaya, Mohanpur

Nadia, West Bengal, India

\section{New record of Phoma leaf spot disease of ruffled fan palm (Licuala grandis) from West Bengal, India}

\author{
Arghya Banerjee and Partha Sarathi Nath
}

\begin{abstract}
Licuala grandis, commonly known as ruffled fan palm, is an important ornamental plant. Recently disease symptoms that resemble those of leaf spot were observed during September to November, 2017, in $2-3$ years old plants, planted in and around Bidhan Chandra Krishi Viswavidyalaya campus of West Bengal, India. Based on the morphological and cultural characters, the disease causing organism was identified as Phoma spp. Conidia, produced on host, were single-celled, hyaline, ovoid-ellipsoidal, sometimes slightly curved, $4.1-7.0 \mu$ (av. $5.5 \mu$ ) x $1.1-2.0 \mu$ (av. $1.7 \mu$ ) in size, but with age becoming minutely roughened.
\end{abstract}

Keywords: Licuala grandis, Leaf spot, Phoma, West Bengal

\section{Introduction}

Licuala grandis is a species of shade loving ornamental palm in the Arecaceae family, native to the wet, humid rain forests of the Republic of Vanuatu and the Solomon Islands east of Australia ${ }^{[2]}$. One of its common names is Ruffled Fan Leaf Palm, due to its showy undulating leaf contour. The plant has immense ornamental value and grown in different Indian gardens. During a recent survey in and around Nadia district, West Bengal, a hitherto unrecorded leaf spot disease of $L$. grandis was noticed. The disease on the plant might be observed at any time of the year but it was most conspicuous during September - November. The specific symptoms along with pathogen of the disease were recorded.

\section{Materials and Methods}

The infected leaves and tissues were collected with the help of a sterilized knife and carried to the laboratory for microscopic observation. Infected leaf tissues were surface sterilized by dipping them in $0.1 \% \mathrm{HgCl}_{2}$ for one minute and then washed with sterilized distilled water. A small portion of the tissue was placed on water agar (WA) plate and incubated at $25^{\circ} \mathrm{C}$ for 7 days. Purification of culture was done on potato dextrose agar (PDA) medium for sporulation of pathogen. Series of slides were prepared from cultures or infected parts for morpho-metric studies of fungal spores, spore bearing structures. Micro-photograph of all fungal structures was taken with help of Leica Binocular Microscope and or Karl Zeis Phase Contrast Microscope and by using Canon Powers Shot A640 camera. Morpho-metric measurements were taken by using AxioVision (Rel. 4.8) software. Pathogenicity test was carried out with the isolated fungus by following detached leaf inoculating technique. After the manifestation of the disease, the symptoms were recorded and compared with the original symptoms. The pathogen was again isolated from the diseased area and verified with the previously isolated cultures.

\section{Results and Discussion}

The infected plants exhibited typical leaf spot symptoms basically on lower to middle leaves. Several small to medium sized grey white spots, sometimes surrounded by light - dark brown irregular margin mostly confined to leaf tip regions were noticed (Plate. 1). In severe condition, the whole leaf on drying appeared to have a burning symptom (Plate. 2) on which numerous ostiolate, semi-immersed, solitary or confluents, sub-globose to globose and light brown to dark brown pycnidia (av. 210.8 $\mu$ ) were formed sub-epidermally (Plate. 3). Conidiophores were not clearly visible. The numerous conidia were exuded through the ostiole. Conidia (Plate. 4) were single-celled, hyaline, ovoid-ellipsoidal, sometimes slightly curved, $4.1-7.0 \mu$ (av. $5.5 \mu) \times 1.1-2.0 \mu$ (av. 1.7 $\mu$ ) in size, but with age becoming minutely 
roughened. On potato dextrose agar medium, the fungus produced thick whitish mycelia superficially. Pycnidia formation was noticed near the surroundings of inoculation. Light brownish to black pigmentation was observed at the bottom surface of the Petri plate. On the basis of microscopic and cultural characters, the genus of the causal pathogen was confirmed as Phoma with the help of keys of Boerema et al. (2004) ${ }^{[1]}$. Pathogenicity test was conducted with the isolated Phoma spp. which fully satisfied the Koch's postulates. So, the causal fungus of presently described leaf spot disease of Licuala grandis being proposed as Phoma spp.from West Bengal, India.
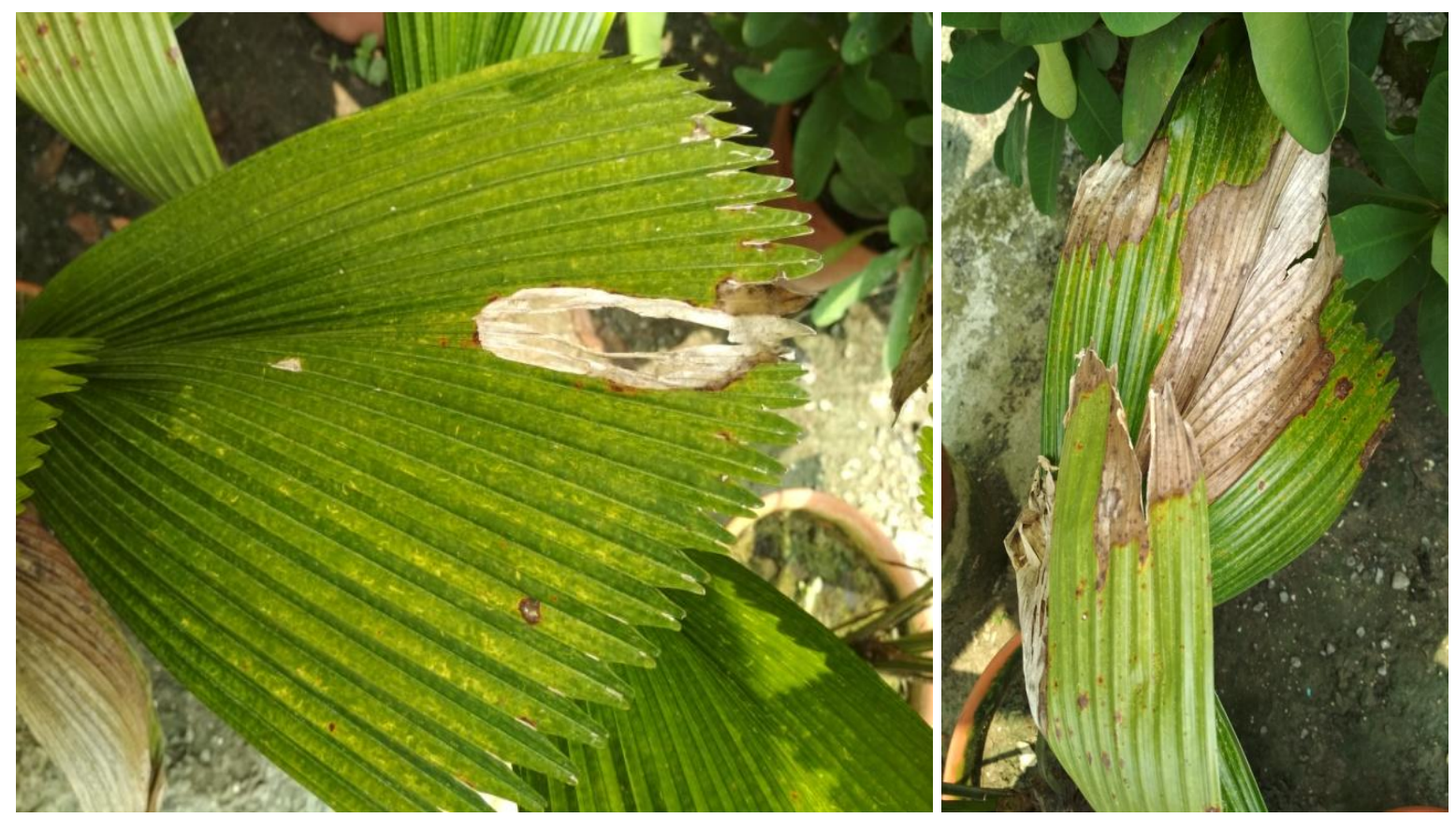

Plate. 1-2: Disease symptoms

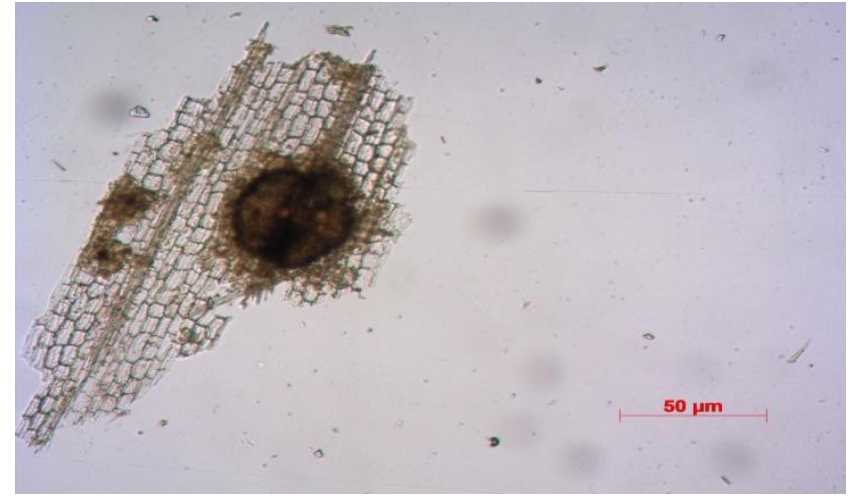

Plate 3: Pycnidium on host

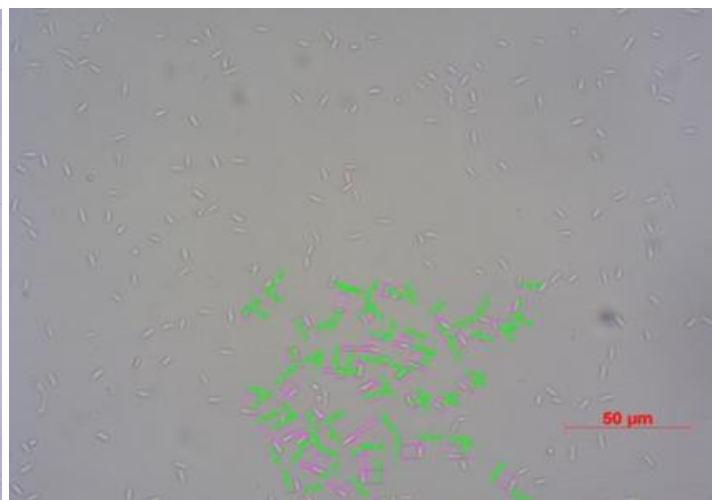

Plate 4: conidia produced on host

\section{References}

1. Boerema GH, Gruyter Jde, Noordeloos ME, Hamers MEC. Phoma identification manual. Differentiation of specific and Intra - specific Taxa in culture. CABI Publishing, CAB International Wallingford, UK. 2004, 478.

2. www.learn2grow.com/plants/licuala-grandis/ 